\title{
Prevalence and Factors Associated with Overweight and Obesity among University Students of the Health Field in San Luis Potosí México
}

\author{
Romo Báez Ana Sofía1, Tejada Tayaba Luz María1 ${ }^{*}$, Pastor Durango María del Pilar², \\ Gaytan Hernández Dario', Norma Angelica Estevis Adame3, \\ Ortiz Villalobos Guillermo ${ }^{3}$ \\ ${ }^{1}$ School of Nursing, Autonomous University of San Luis Potosí, San Luis Potosí, Mexico \\ ${ }^{2}$ School of Nursing, The University of Antioquia, Medellín, Colombia \\ ${ }^{3}$ Health Services in the State of San Luis Potosi, San Luis Potosí, Mexico \\ Email: sophiaromo@hotmail.com, ${ }^{*}$ Itejada@uaslp.mx, ppastordurango@gmail.com, dgaytan@uaslp.mx, \\ angelizaestevis29@hotmail.com, memoartemx@yahoo.com.mx
}

Received 13 February 2015; accepted 10 March 2015; published 13 March 2015

Copyright (C) 2015 by authors and Scientific Research Publishing Inc.

This work is licensed under the Creative Commons Attribution International License (CC BY).

http://creativecommons.org/licenses/by/4.0/

(c) $\underset{\mathrm{EY}}{0}$ Open Access

\begin{abstract}
The aim for this research is to determine the association between the risk factors and prevalence of overweight and obesity in students in the health field in the Autonomous University of San Luis Potosí (UASLP in Spanish). A quantitative, correlational, and cross-sectional study was conducted from May to November 2012. By stratified random sampling, 290 students in the health field were selected. Questionnaire was used to identify factors associated with obesity. The obesity and overweight prevalence was determined, calculating body mass index through anthropometric measurement. The strength of the association between variables was measured using Chi squared and odds ratio tests. The proportion of students with overweight or obesity was $28.3 \%$ and was higher in men $(36.8 \%)$ than in women $(24.6 \%)$, with statistical significance $(p<0.01)$. Greater obesity or overweight was identified in psychology students $(p<0.01)$ and in those who reported an average appetite $(79.3 \%)(p<0.05)$. In total, $66.6 \%$ of the students decreased their physical activity upon joining the university, which was a factor significantly associated with obesity and overweight $(p<0.05)$. The findings show that the school environment can be a conditioning factor for the development of obesity and overweight in students. Implementation of a program is recommended to prevent and control such problems.
\end{abstract}

\footnotetext{
${ }^{*}$ Corresponding author.
}

How to cite this paper: Sofía, R.B.A., María, T.T.L., del Pilar, P.D.M., Dario, G.H., Adame, N.A.E. and Guillermo, O.V. (2015) Prevalence and Factors Associated with Overweight and Obesity among University Students of the Health Field in San Luis Potosí México. Health, 7, 328-335. http://dx.doi.org/10.4236/health.2015.73037 


\section{Keywords}

\section{University Students, Obesity, Risk Factors}

\section{Introduction}

Obesity and overweight are considered a public health problem due to their high prevalence in different age groups, mainly in young adults [1], as well as the short, medium, and long term consequences because obesity is one of the major disorders associated with the development of chronic degenerative diseases and their complications, with a consequent decrease in life expectancy and quality of life in the affected people [2]. In fact, obesity is linked to $60 \%$ of deaths due to noncommunicable diseases [3].

Figures reported in 2010 by the World Health Organization [4], indicate that worldwide, approximately one billion people over the age of 20 are overweight and that more than 300 million are obese. Additionally, it is estimated that in 2015, there will be approximately 1.5 billion overweight and 700 million obese adults.

Mexico ranks second globally in obesity in the adult population, with 52.2 million people affected. Adding the prevalence of both overweight and obesity, the results reveal a combined prevalence in women over 20 years of $73 \%$ and in men $69.4 \%$ [5].

One of the population groups vulnerable to the problems of obesity and overweight are university students due to factors such as increased energy needs by age, increased consumption of foods rich in fat and calories, decreased physical activity, and emotional changes (mainly anxiety and depression) that stimulate food intake [6]. Additionally, the school context in which they spend most of the day may have unfavorable conditions that make it difficult to adopt and maintain healthy habits [7].

Regarding obesity and overweight in the university population, there have been several studies, some focused on assessing eating behaviors and risk factors [8] others on determining the prevalence and consequences of obesity and overweight [3]. Some studies show increased food consumption, lack of physical activity, and their association with overweight and obesity in university students [9]-[11]. Other studies [12]-[14] identify psychosocial factors of specific risk such as certain family conditions associated with obesity in young people. This study presents the association between different risk factors, without delimiting any in particular, and the investigation was aimed to lay the groundwork and justify the design and implementation of an intervention program that promotes healthy habits that counteract factors associated with weight problems in this population. The intervention will be developed through the Institutional Program of Health Promotion (PIPS, in Spanish) and will be addressed to the total population of university students.

The study subjects were enrolled students majoring in health area, considering them potential agents of change, with cognitive and perceptual characteristics that are modifiable by situational, personal, and interpersonal factors that facilitate the development of health-promoting behaviors when there is a guide for action [15]. Additionally, when the intervention is implemented in PIPS, they will be considered and invited to participate as promoters in the aforementioned program.

The objective that guided this study was determining the association between the prevalence of obesity and overweight and the different risk factors present in students in the health field at the Autonomous University of San Luis Potosi (UASLP, in Spanish).

\section{Materials and Methods}

This work is part of the study called Social and Cultural Determinants of Obesity, which is a comparative perspective of university students in two states of Mexico and is funded by the Institute of Nutrition and Kellogg's Health.

A quantitative, correlational, and cross-sectional study was conducted at the Autonomous University of San Luis Potosi, Mexico, with students in the health field majoring in nursing, medicine, environmental sciences and health, stomatology, nutrition, pharmacobiologic chemistry, and psychology during from May to November 2012.

From the total alumni of such majors (3800) through the Epidat 3.1 program, a sample size of 290 students was calculated, with the following parameters: a 5\% expected proportion, $3 \%$ maximum error, $95 \%$ confidence, and a design effect of 1.5. The sample was stratified for each of the majors considered in the study. Participants were selected by simple random sampling. Male and female students enrolled in the 2012-2013 school year between ages of 18 and 29 were included. 
To collect information on risk factors, a structured questionnaire was applied with items obtained from other validated surveys, which were selected according to study objectives [16]-[19]. The instrument was structured with the following sections: a) sociodemographic data; b) heredofamilial history; c) food consumption patterns, d) appetite and food perception, e) source of foods consumed; f) physical activity; and g) Goldberg scale to identify presumptive symptoms of anxiety and depression. In the pilot test of the instrument, a reliability of 0.756 was obtained.

The body mass index of the participants was obtained from anthropometric measurements of weight and height, which were obtained by the principal investigator using a portable SECA brand stadiometer and scale. To determine the presence of overweight and obesity, the classifications and parameters proposed by WHO were used [4].

Data analysis was performed by applying descriptive statistics measures such as absolute and relative frequencies as well as measures of central tendency and dispersion. To identify associations between the risk factors and prevalence of obesity, inferential statistics were used with Chi-squared tests; with respect to the estimation of risk and protective factors, the odds ratio was applied with $95 \%$ confidence intervals.

The study was approved by the Research Ethics Committee of UASLP. Participants signed a letter of informed consent.

\section{Results}

\subsection{Sociodemographic Characteristics and Heredofamilial Background of the Study Participants}

Of all of the students surveyed, the highest proportion was in the age range of 18 to 20 years, with an average of 21 years and a standard deviation of 2.1 years. Seventy percent (203) were women, and 30\% (87) were men. In total, $90.3 \%$ of the young participants were born in San Luis Potosi, and the majority (95.2\%) resided in the state capital.

Regarding the presence of heredofamilial factors, $87.6 \%$ of surveyed students reporteda diagnosis of chronic degenerative disease, in either a parent (30\%) or grandparent (42.5\%) and brothers (15.1\%) (Table 1).

\subsection{Prevalence of Obesity/Overweight and Associated Factors}

Regarding the prevalence of obesity, 9.6\% of the students in the study group had some degree of obesity, and the proportion of young people with overweight was $19.7 \%$. Adding both problems in a combined prevalence, as suggested by the National Health Survey [5] to yield a realistic perspective of risk, the result amounted to 28.3\% of students affected, indicating that one in three students on average have any of these weight problems. The findings also indicated that the prevalence of some degree of obesity in both sexes was $21.9 \%$ of young people; this prevalence was higher in males (17.3\%) than in females (reaching $4.9 \%)$. A statistically significant association ( $<<0.01$ ) was found between male sex and obesity prevalence (Table 2).

Table 1. Sociodemographic characteristics and heredofamilial background of the study participants. UASLP, San Luis Potosí, SLP, 2012.

\begin{tabular}{|c|c|c|c|}
\hline Characteristic & & $\mathrm{n}$ & $\%$ \\
\hline \multirow{2}{*}{ Sex } & Female & 203 & 70 \\
\hline & Male & 87 & 30 \\
\hline \multirow{3}{*}{ Age } & $17-20$ & 167 & 57.6 \\
\hline & $21-24$ & 100 & 34.5 \\
\hline & 25andmore & 23 & 7.9 \\
\hline \multirow{2}{*}{ Place of birth } & In the state of San Luis Potosí & 262 & 90.3 \\
\hline & In another location & 28 & 9.7 \\
\hline \multirow{2}{*}{ Residence } & In the state capital & 276 & 95.2 \\
\hline & In another location & 14 & 4.8 \\
\hline \multirow{2}{*}{ Heredofamilial factors } & Parents with chronic degenerative disease & 254 & 87.6 \\
\hline & Without factors & 36 & 12.4 \\
\hline
\end{tabular}

Source: Author's calculation based on data obtained with the instrument risk factors of obesity. 
Table 2. Body mass index by sex of students in the health field: UASLP, San Luis Potosí, SLP, 2012.

\begin{tabular}{|c|c|c|c|c|c|c|}
\hline \multirow{3}{*}{ Diagnosis } & \multicolumn{4}{|c|}{ Sex } & \multirow{2}{*}{\multicolumn{2}{|c|}{ Total }} \\
\hline & \multirow{2}{*}{$\begin{array}{c}\text { Female } \\
\mathrm{n}\end{array}$} & \multicolumn{3}{|c|}{ Male } & & \\
\hline & & $\%$ & $\mathrm{n}$ & $\%$ & $\mathrm{n}$ & $\%$ \\
\hline Normal weight & 153 & 75.4 & 55 & 63.2 & 208 & 71.7 \\
\hline Overweight & 40 & 19.7 & 17 & 19.5 & 57 & 19.7 \\
\hline Grade 1 obesity & 9 & 4.4 & 13 & 14.9 & 22 & 7.6 \\
\hline Grade 2 obesity & 1 & 0.5 & 2 & 2.4 & 3 & 1.0 \\
\hline Total & 203 & 100.0 & 87 & 100.0 & 290 & 100.0 \\
\hline
\end{tabular}

Source: Author's calculation based on data obtained with the instrument risk factors of obesity $(\mathrm{p}<0.01)$.

Upon analyzing data on the prevalence of obesity and overweight among students in different health majors, it was identified that psychology majors accounted for the greatest proportion of youth with overweight (33.3\%), followed by majors in nursing (22.8\%) and medicine (21.1\%). With regard to obesity, the highest proportion of young people in the pharmacobiologic chemistry major $(28.0 \%)$ had this problem, followed by the nursing (20.0\%), psychology (16\%), and medicine majors (16\%). By contrast, the lowest percentage of students with weight problems corresponded to the majors innutrition and environmental sciences, in which no young people with overweight problems were identified and only 4\% were obese. The data analysis revealed a statistically significant association ( $\mathrm{p}<0.01$ ) between field of study and the presence of obesity or overweight (Table 3).

Regarding appetite perception, it was observed that $79.3 \%$ of students with overweight/obesity had an average appetite perception; there was a statistically significant association $(p<0.05)$ between perceived appetite and the presence of overweight and obesity (Table 4).

Additionally, the findings revealed a high proportion (59.8\%) of students with overweight/obesity experiencing a greater appetite during the evening and increased food consumption at that time. A statistically significant association $(\mathrm{p}<0.05)$ was found between the time of day they experienced increased appetite and consumed more food and the presence of overweight/obesity (Table 5).

Furthermore, $56.1 \%$ of students with overweight/obesity had decreased their physical activity upon entering the university. A statistically significant association $(\mathrm{p}<0.05)$ was identified between both variables (Table 6).

The data on presumptive symptoms of anxiety showed that $28.9 \%$ of students with overweight/obesity displayed signs of anxiety; however, no statistically significant association ( $p>0.05$ ) was found between this problem and the presence of overweight/obesity. Furthermore, presumptive depressive symptoms reported by the students demonstrated that $30.6 \%$ of students with overweight/obesity had such symptoms, without any statistically significant association $(\mathrm{p}>0.05)$ between these variables.

When measuring the strength of the association between the prevalence of overweight/obesity and some of the risk factors, the following was observed: the risk of being an obese man was 1.7 times the risk of being anobese woman; individuals who were studying psychology had a 3.15-fold risk of becoming overweight or obese compared with those studying stomatology, but no difference was identified in other majors. Likewise, there was a 21.8-fold risk of obesity among individuals who bought their food on campus compared with those who did not.

\section{Discussion}

Results regarding the prevalence of overweight and obesity obtained in this study present a different picture than the findings reported by the National Health Survey [5], which reported considerably larger figures nationwide for these problems. Perhaps this difference is due to the individuals included in this study, which were found in the lower range of parameters considered for the population of early adulthood spanning from 15 to 29 years; it is also noteworthy that the sample was delimited to university students in the health field, who are considered more knowledgeable about these problems, as well as their protective and risk factors. However, the figures indicate the need for a timely intervention on this issue to prevent and control risk factors, given that the school environment may favor the emergence and development of overweight and obesity. 
Table 3. Field of study and prevalence of obesity and overweight in students in the health field: UASLP, San Luis Potosí, SLP, 2012.

\begin{tabular}{lccccccccc}
\hline Major & \multicolumn{2}{c}{ Normal } & \multicolumn{2}{c}{ Ovight } & \multicolumn{2}{c}{ Oberweight } & \multicolumn{2}{c}{ Total } \\
& $\mathrm{n}$ & $\%$ & $\mathrm{n}$ & $\%$ & $\mathrm{n}$ & $\%$ & $\mathrm{n}$ & $\%$ \\
\hline Nursing & 33 & 15.9 & 13 & 22.8 & 5 & 20.0 & 51 & 17.6 \\
Nutrition & 17 & 8.2 & 0 & 0 & 1 & $4.0 \%$ & 18 & 6.2 \\
Stomatology & 58 & 27.9 & 6 & 10.5 & 3 & 12.0 & 67 & 23.1 \\
Pharmacobiologic chemistry & 21 & 10.1 & 7 & 12.3 & 7 & 28.0 & 35 & 12.1 \\
Environmental sciences & 3 & 1.4 & 0 & 0 & 1 & 4.0 & 4 & 1.4 \\
Psychology & 47 & 22.6 & 19 & 33.3 & 4 & 16.0 & 70 & 24.1 \\
Medicine & 29 & 13.9 & 12 & 21.1 & 4 & 16.0 & 45 & 15.5 \\
Total & 208 & 100.0 & 57 & 100.0 & 25 & 100.0 & 290 & 100.0 \\
\hline
\end{tabular}

Source: Author's calculation based on data obtained with the instrument risk factors of obesity (p $<0.05)$.

Table 4. Appetite scale according to the normal weight/overweight/obesity classification: UASLP, San Luis Potosí, SLP, 2012.

\begin{tabular}{cccccccc}
\hline & \multicolumn{2}{c}{ Normal weight } & \multicolumn{2}{c}{ Overweight/obesity } & \multicolumn{3}{c}{ Total } \\
\hline Appetite scale & Fx & $\%$ & Fx & $\%$ & Fx & $\%$ \\
\hline 1. Reduced appetite & 2 & 1.0 & 1 & 1.2 & 3 & 1.0 \\
2. Moderate appetite & 190 & 91.3 & 65 & 79.3 & 255 & 87.9 \\
3. Increased appetite & 16 & 7.7 & 16 & 19.5 & 32 & 11.0 \\
Total & 208 & 100.0 & 82 & 100.0 & 290 & 100.0 \\
\hline
\end{tabular}

Source: Author's calculation based on data obtained with the instrument risk factors of obesity (p $<0.05)$.

Table 5. Time of day of increased appetite according to the normal weight/overweight/obesity classification: UASLP, San Luis Potosí, SLP, 2012.

\begin{tabular}{|c|c|c|c|c|c|c|c|}
\hline \multirow{2}{*}{ Time of Day } & & \multicolumn{2}{|c|}{ Normal weight } & \multicolumn{2}{|c|}{ Overweight/obesity } & \multicolumn{2}{|c|}{ Total } \\
\hline & & $\mathrm{Fx}$ & $\%$ & $\mathrm{Fx}$ & $\%$ & Fx & $\%$ \\
\hline & Morning & 18 & 8.7 & 13 & 15.9 & 31 & 10.7 \\
\hline & Midday & 6 & 2.9 & 4 & 4.9 & 10 & 3.4 \\
\hline & Afternoon & 164 & 78.8 & 49 & 59.8 & 213 & 73.4 \\
\hline & Night & 20 & 9.6 & 16 & 19.5 & 36 & 12.4 \\
\hline & Total & 208 & 100.0 & 82 & 100.0 & 290 & 100.0 \\
\hline
\end{tabular}

Source: Author's calculation based on data obtained with the instrument risk factors of obesity ( $<<0.01)$.

Table 6. Physical activity upon entering the university, according to the normal weight/overweight/obesity classification: UASLP, San Luis Potosí, SLP, 2012.

\begin{tabular}{|c|c|c|c|c|c|c|}
\hline \multirow{2}{*}{ Physical Activity } & \multicolumn{2}{|c|}{ Normal Weight } & \multicolumn{2}{|c|}{ Overweight/Obesity } & \multicolumn{2}{|c|}{ Total } \\
\hline & Fx & $\%$ & $\mathrm{Fx}$ & $\%$ & Fx & $\%$ \\
\hline Increased & 26 & 12.5 & 19 & 23.2 & 45 & 15.5 \\
\hline Decreased & 147 & 70.7 & 46 & 56.1 & 193 & 66.6 \\
\hline Same & 35 & 16.8 & 17 & 20.7 & 52 & 17.9 \\
\hline Total & 208 & 100.0 & 82 & 100.0 & 290 & 100.0 \\
\hline
\end{tabular}

Source: Author's calculation based on data obtained with the instrument risk factors of obesity (p $<0.05)$. 
Although the prevalence of obesity was not higher in the study population, the problem is exacerbated when considering the small difference between overweight and obesity and the tendency for overweight people to present short-term obesity [20].

Considering that the average age of the study population was 21 years, students who are overweight or obese can be considered more susceptible to chronic disease in the short or medium term, further considering their inherited family history because most students included in the study (87.6\%) were positively in direct line for these types of diseases. In this regard, several studies [3] [21] argue that obesity in adulthood and its associated health problems are strongly associated with the weight levels of the individuals in their childhood and youth; thus it can be predicted that failure to establish permanent, preventative control measures will, in the short term, lead to a high percentage of health problems related to obesity among young college students, and the consequences will pose a greater challenge to overcome.

In this study, a greater proportion of obesity problems were identified in male students. These data differ from those reported by the National Health Survey [5], which revealed higher percentages of obesity in women. This discrepancy may be related to the age of the participants in the present study, in which those over 29 years old were not considered; thus, this investigation excluded ages associated with climacteric and menopause, during which the tendency for women to present obesity is greater.

Another noteworthy finding is that the food quality tended to decrease during the transition of young people to university and that the vast majority of the university students had unhealthy eating habits, similar results have been reported by other studies [10] [21]. Moreover, in the present study, the physical activity of the young people decreased upon entering the university; this finding was consistent with other investigations [7] [22].

A significant fact is the association between hours of increased appetite and increased food consumption and the combined prevalence of obesity and overweight; a common habit among young people is prolonged fasting culminating in the excessive consumption of high-calorie and high-fat foods during the afternoon or evening, which alters the metabolism and causes insulin resistance, predisposing individuals to obesity [23].

It is clear that obesity, in most cases, is due to an imbalance between intake (food) and/or caloric output (metabolism and exercise). Undoubtedly, the two factors are environmental in nature and are therefore susceptible to change with preventative measures. Furthermore, although the obesity issue is complex, if these two factors are identified and resolved, the problems would theoretically decrease.

Prevention and control of these factors represents a challenge for universities in their vision to remain healthy institutions, and thus it is appropriate to propose and implement a comprehensive program that will be derived and justified by the results of this study and will sustain itself in the Nola Pender [15] model of health promotion.

The program will have three levels of action: a) structural; b) collective; and c) individual. At the first level (structural), arrangements will be developed with the participation of professors and students to propose to university authorities establishing initiatives for there to be more areas in university spaces and available time for scheduled physical activities. Similarly, the establishment of academic schedules that facilitate both exercising and consuming food at sufficient and appropriate times will be suggested. All of these factors will facilitate dietary habits and physical activity among university students. Likewise, regulations regarding the sale of healthy foods at affordable costs for young people within the university campus will be promoted.

At the second level (collective), a permanent campaign of nutritional education and promotion of physical activity will be established with the active participation of students. At the third level (individual), permanent actions for detecting and controlling obesity and overweight will be systematized in all health care units for students contained by PIPS in the different faculties, which are attended by professionals and interns in the nursing social service. Another activity will be the dissemination in all schools of the UASLP of permanent services of the University Center for Nutritional Care (CUAN, in Spanish) for education and nutritional consultations, which is located at and under the coordination of the School of Nursing. Implementation of this program aims to reduce environmental risks and promote healthy lifestyles among young people.

This study has certain limitations, such as the sample, which although representative in number, delimits only one group of students (in the health field), and thus, it would be appropriate to perform research considering alumni from all university majors to gain a more complete picture of the problem. Furthermore, as part of the overall research (inquiring from qualitative approaches as other studies have done the perceptions, meanings, and practices of college students regarding the determinants of obesity and its consequences), the aim is toelucidate the particularities of obesity and the various expressions of the food consumption-sedentary lifestyle- 
increased weight process within the university context.

\section{Conclusion}

The results of this study reveal that this population group is more vulnerable to overweight and obesity because of the imbalance between dietary intake and physical activity that is determined by factors associated with the environment and lifestyle of young people-mainly due to the special conditions of the school environment that appear to establish behavior patterns characterized by unhealthy habits. By failing to act promptly to prevent and control these problems, young people will be affected by the consequences of obesity in the medium and long term, with the appearance of multiple diseases and complications that may reduce life expectancies and seriously affect their productive life. This study and the program derived from its results enable assessing the significance of the role of nursing in exercising leadership roles, management, and assistance for promoting and maintaining the health of various population groups.

\section{Acknowledgements}

The authors thank the Institute of Nutrition and Health, Kellogg's (INSK in Spanish) for the support provided to complete this study.

\section{References}

[1] Barquera, S. and Tolentino, L. (2010) Obesity and Diabetes in Mexico: Increasing Public Health Problems. In: Chapela, M., Ed., In the Debate: Diabetes in Mexico, [In Spanish], Universidad Autónoma Metropolitana (UAM) Xochimilco, México, 53-85.

[2] Biro, F.M. and Wien, M. (2010) Childhood Obesity and Adult Morbidities. The American Journal of Clinical Nutrition, 91, 1499S-1505S. http://ajcn.nutrition.org/content/91/5/1499S.full.pdf \pm html http://dx.doi.org/10.3945/ajcn.2010.28701B

[3] Soca, P. and Alvett, P. (2009) Consequences of Obesity. Acimed, 20, 84-92. http://scielo.sld.cu/pdf/aci/v20n4/aci061009.pdf

[4] World Health Organization (2010) Obesity and Overweight. Obesity Report. 10 Facts on Obesity, Technical Report Series 207. http://www.who.int/features/factfiles/obesity/facts/es/index1.html

[5] National Health and Nutrition Survey (ENSANUT) (2012) National Results. Nutrition/Adults. Instituto Nacional de Salud Pública, 180-186.

[6] Carretero, A., Sánchez, L., Estragués, J., Raich, R. and Sánchez, D. (2010) Relevant Risk Factors, Current Eating Psychopathology, Body Shape Concern and Psychological Functioning in Eating Disorders. Psychology in Spain, 14, 3241. http://www.psychologyinspain.com/content/full/2010/14005.pdf

[7] Lloyd-Richardson, E., Bailey, S., Fava, J. and Wing, R. (2009) A Prospective Study of Weight Gain during the College Freshman and Sophomore Years. Preventive Medicine, 48, 256-261. http://www.ncbi.nlm.nih.gov/pmc/articles/PMC2696183/pdf/nihms106678.pdf http://dx.doi.org/10.1016/j.ypmed.2008.12.009

[8] Guerra, C., Vila, J., Apolinaire, J., Cabrera, A., Santana, I. and Almaguer, P. (2009) Risk Factors Associated with Overweight and Obesity in Adolescents. MediSur, 7, 25-34. http://scielo.sld.cu/pdf/ms/v7n2/v7n2a632

[9] Macmillan, K. (2007) Assessing Eating Habits, Physical Activity and Nutritional Status among Students from the Catholic University of Valparaiso. Revista Chilena de Nutrición, 34, 330-336. http://www.scielo.cl/scielo.php?script=sci_arttext\&pid=S0717-75182007000400006

[10] Vargas, M., Becerra, F. and Prieto, S. (2010) Assessment of Dietary Intake among College Students, Bogotá, Colombia. Revista de Salud Pública, 12, 116-125. http://www.scielosp.org/pdf/rsap/v12n1/v12n1a11.pdf

[11] Vázquez, M. and Writim, A. (2010) Preliminary Study on Dietary Intake among College Students in the Majors of Medicine and Architecture at the University of Buenos Aires. Diaeta, 28, 14-17. http://www.scielo.org.ar/pdf/diaeta/v28n131/v28n131a03.pdf

[12] Troncoso, P. and Amaya, C. (2009) Social Factors in Eating Behaviors of College Students. Revista Chilena de Nutrición, 36, 1090-1097. http://www.scielo.cl/pdf/rchnut/v36n4/art05.pdf

[13] Calderon, C., Forns, M. and Varea, V. (2010) Involvement of Anxiety and Depression in Eating Disorders of Young Obese People. Nutricion Hospitalaria, 25, 641-647. http://scielo.isciii.es/pdf/nh/v25n4/original13.pdf

[14] Kubzansky, L., Gilthorpe, M.S. and Goodman, E. (2011) Prospective Study of Psychological Distress and Weight Sta- 
tus in Adolescents/Young Adults. Annals of Behavioral Medicine, 43, 219-228.

http://europepmc.org/articles/PMC3381504?pdf=render

http://dx.doi.org/10.1007/s12160-011-9323-8

[15] Sakraida, J. (2007) Health Promotion Model Nola J Pender. In: Marriner, A. and Raile-Alligood, M., Eds., Models and Theories of Nursing, 6th Edition. Elsevier-Mosby, Span, 289-297.

[16] Goldberg, D. (1988) Detection Scale of Anxiety and Depression. http://salpub.uv.es/SALPUB/pspic/docs/Escalas \pm Instrum_valoracion_atencion_domiciliaria/085_ESCALA_ANSIEDA D_DEPRESION_GOLDBERG.pdf

[17] Unikel, C., Letza, C. and Carreño, S. (2004) Validation of a Short Questionnaire to Measure Dietary Risk Behaviors Revista Salud Pública de México, 46, 509-515. http://www.scielo.br/pdf/spm/v46n6/22563.pdf

[18] Department of Chronic Diseases and Health Promotion (2004) Population-Based Surveillance and Prevention of the World Health Organization. Global Physical Activity Questionnaire GPAQ Ginebra Suiza. http://www.sdprc.org/lhn-tools/gpaq-spanish.pdf

[19] National Center for Health Statistics (2009) NHANES Dietary Habits Questionnaire III. U.S. http://www.cdc.gov/nchs/data/nhanes/nhanes_09_10/dbq_f.pdf

[20] Menezes, C., Neutzling, B. and Aguiar, A. (2009) Risk Factor for Overweight and Obesity in Adolescents of a Brazilian University: A Case-Control Study. Nutricion Hospitalaria, 24, 17-24. http://scielo.isciii.es/pdf/nh/v24n1/original1.pdf

[21] Trujillo, B., Vazquez, C., Almanza, J., Jaramillo, M., Medellin, T. and Valle, O. (2010) Frequency and Risk Factors Associated with Overweight and Obesity in University Students of Colima. Revista de Salud Pública, 12, 197-207. http://www.scielosp.org/pdf/rsap/v12n2/v12n2a03.pdf

[22] Farinola, M. and Bazan, N.E. (2011) Sedentary Behavior and Physical Activity in College Students: A Pilot Study. Revista Argentina de Cardiología, 79, 351-354. http://www.scielo.org.ar/pdf/rac/v79n4/v79n4a08.pdf

[23] Rogero, M.L., Albanil, M.R., Sánchez, M., Rabanal, A., Olivas, A. and García, C. (2012) Prevalence of Insulin Resistance in a Young Adult Population. Relationship with Weight Status. Endocrinología y Nutrición, 59, 98-104. 